\title{
Catalytical Specificity, Reaction Mechanisms, and Conformational Changes during Catalysis of the Recombinant SUMO (+)-Zizaene Synthase from Chrysopogon zizanioides
}

\author{
Francisco Aguilar, ${ }^{\dagger, \dagger}$ Stephan Hartwig, ${ }^{\dagger}$ Thomas Scheper, $^{\dagger}$ and Sascha Beutel ${ }^{*}{ }^{\dagger}$ (1) \\ ${ }^{\dagger}$ Institute of Technical Chemistry, Leibniz University of Hannover, Callinstr. 5, 30167 Hannover, Germany \\ ${ }^{\ddagger}$ National Center for Biotechnological Innovations of Costa Rica-CENIBiot, 1174-1200 San José, Costa Rica
}

Supporting Information

\begin{abstract}
Zizaene synthase (ZS) from Chrysopogon zizanioides (Poaceae) is the critical enzyme in the biosynthesis of the fragrant sesquiterpene khusimol, a major component of the vetiver essential oil used widely by the cosmetic industry. As reported previously, we heterologously and successfully expressed the active ZS with a small ubiquitin-related modifier (SUMO) fusion domain. In this study, we report the optimization of reaction conditions and determination of enzyme kinetics of ZS. Moreover, we investigate the catalytic specificity and reaction mechanisms with the ubiquitous $(2 E, 6 E)$-farnesyl diphosphate (FDP) and with $\mathrm{C}_{10}$ and $\mathrm{C}_{15}$ prenyl diphosphate isomers. Catalytic promiscuity occurs with monoterpene substrates generating eight products that

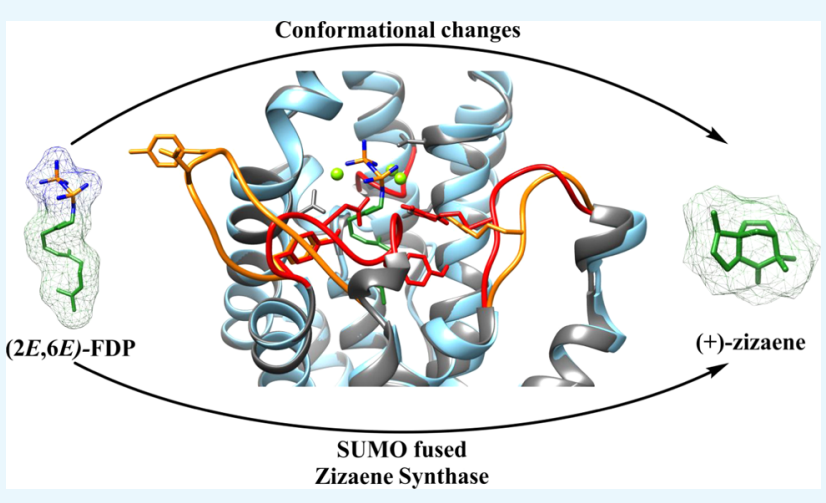
comprise acyclic, cyclic, and hydroxylated monoterpenes. In contrast, ZS is a high-fidelity terpene cyclase when used with $\mathrm{C}_{15}$ isomer substrates, yielding as major products $(Z)-\beta$-farnesene $(100 \%)$ for $(2 E, 6 Z)$-FDP and $(+)$-zizaene $(81.7 \%), \beta$ acoradiene $(12.8 \%)$, and $(E)-\beta$-farnesene $(5.5 \%)$ for $(2 Z, 6 E)$-FDP. Cyclization of the ubiquitous substrate (2E,6E)-FDP demonstrates a higher catalytic specificity, whereas the reaction proceeds via the acorenyl cation that generates (+)-zizaene (91.5\%) and $\beta$-acoradiene (8.5\%). Furthermore, catalytic specificity with (2E,6E)-FDP was stable in reactions tested at distinct $\mathrm{pH}$ and temperatures, suggesting a stable and efficient closed conformation of the active site during catalysis. To understand such stability, open and closed structural conformations of ZS were modeled in silico and revealed putative residues in the active site and in the A-C and J-K surrounding loops, which could explain the high fidelity of ZS.
\end{abstract}

\section{INTRODUCTION}

Sesquiterpene cyclases (STC) catalyze more than 300 distinct $\mathrm{C}_{15}$ carbon skeletons, giving origin to a variety of sesquiterpene lactones, ketones, alcohols, and aldehydes, which are the main constituents of plant essential oils, many used for flavor and fragrant applications. ${ }^{1-3}$ STC are metal-dependent enzymes that catalyze the conversion of the universal sesquiterpene substrate $(2 E, 6 E)$-FDP, which originates from isopentenyl diphosphate and dimethylallyl diphosphate from the mevalonic acid pathway that operates in the cellular cytosol. ${ }^{4}$ Their structure includes the active class I terpenoid synthase fold, which contains the conserved aspartate-rich motifs DDXXD and DTE/NSE located in the $\alpha$-helices. ${ }^{5}$ Plant STC also contains an $\mathrm{N}$-terminal domain resembling the class II terpenoid synthase fold with no specific catalytic activity. ${ }^{1}$

The reaction mechanisms of plant STC initiate through the binding of divalent metal ions, mostly $\mathrm{Mg}^{2+}$, to the conserved aspartate-rich motifs, which in turn coordinate the binding of the phosphate moiety $\left(\mathrm{PP}_{\mathrm{i}}\right)$ from FDP by hydrogen bonds. ${ }^{6}$ Thereafter, the enzyme undergoes a conformational change in which the surrounding loops seal the active site, creating a hydrophobic environment that prevents solvent entry. ${ }^{7-9}$ Consequently, the substrate undergoes ionization; thus, $\mathrm{PP}_{\mathrm{i}}$ is cleaved and a transoid-allylic carbocation (farnesyl cation) is generated. At this point, the reaction can be quenched to generate linear cisoid or transoid sesquiterpenes, such as $(E)-\beta$ farnesene ${ }^{10}$ or can undergo cyclizations by two pathways: (1) farnesyl cation undergoes immediate 10,1-cyclization for $(E, E)$-germacradienyl cation or 11,1-cyclization for $(E, E)$ humulyl cation. (2) farnesyl cation undergoes isomerization, leading to the cisoid nerolidyl cation, followed by further cyclizations and generates distinct intermediates: bisabolyl cation (1,6-cyclization), cycloheptanyl cation (1,7-cyclization), $(Z, E)$-germacradienyl cation (1,10-cyclization), or (Z)-humulyl cation (1,11-cyclization). ${ }^{11}$ Further reactions comprise carbocation rearrangements, hydride shifts, and cyclizations, which finalize by deprotonation quenching; thus, the

Received: January 26, 2019

Accepted: March 1, 2019

Published: April 3, 2019 
possibilities for rearrangements are vast and lead to a particular product spectrum. ${ }^{12}$

The active site of each STC is characterized by a specific conformation of residues, especially aromatic residues, which guide the reactions of the prenyl tail and determines the product specificity. ${ }^{6,11}$ For this reason, some STC generate multiple products and are considered promiscuous, such as $\gamma$ humulene synthase, which produces more than 52 products. ${ }^{13}$ Nevertheless, most STC generate few products and therefore are considered high-fidelity enzymes, as shown by tobacco 5epi-aristolochene synthase (TEAS) that generates epi-aristolochene, the precursor for the plant defense compound capsidiol. ${ }^{8}$ Most STC are promiscuous in catalyzing alternative substrates, accepting isoprene diphosphate substrates and

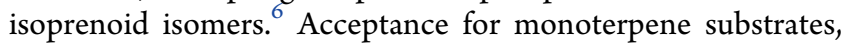
such as the ubiquitous geranyl diphosphate (GPP), has been reported elsewhere. ${ }^{14,15}$ Moreover, acceptance of both GPP and cisoid neryl diphosphate (NPP) has been demonstrated by the patchoulol synthase. ${ }^{16}$ STC are also prone to accept isomers from the sesquiterpene substrate $(2 E, 6 E)$-FDP, whereas catalyzation of isomers $(2 Z, 6 Z)-F D P,{ }^{17}(2 Z, 6 E)$ FDP, ${ }^{18}$ and $(\mathrm{ZE}, 6 \mathrm{Z})-\mathrm{FDP}^{16}$ has been reported.

Of particular interest is the sesquiterpene khusimol, contained in the vetiver essential oil from the tropical grass Ch. zizanioides and used in nearly $20 \%$ of men's perfumes due to its woody smell. ${ }^{19}$ Further research has focused on its medicinal properties and has reported antioxidant, ${ }^{20}$ antimicrobial, ${ }^{21}$ and anti-inflammatory activity. ${ }^{22}$ Together with $\alpha$ and $\beta$-vetivone, khusimol is one of its main constituents and its industrial extraction is performed by steam distillation from dried roots. $^{23}$

Despite its importance, there are few studies concerning the biosynthesis of khusimol, which is most relevant to the development of a biotechnological process. Previously, our group described the heterologous expression in Escherichia coli of ZS from Ch. zizanioides, which is the key enzyme in the biosynthesis of khusimol. ${ }^{24} \mathrm{ZS}$ was expressed fused with the SUMO domain in the N-terminal section to improve solubility, yielding a $64 \mathrm{kDa}$ enzyme. $\mathrm{ZS}$ catalytical functionality was demonstrated by the cyclization of $(2 E, 6 E)$-FDP, which generated the three-cyclic sesquiterpene (+)-zizaene (syn. khusimene), the precursor for khusimol. However, further knowledge is still required to understand the complex enzymatic mechanisms of ZS. Hereby, we report for the first time to our knowledge the product spectrum and reaction mechanisms involved in ZS with the ubiquitous substrate $(2 E, 6 E)-\mathrm{FDP}$ and the alternative substrates NPP, GPP, (2E,6Z)-FDP, and (2Z,6E)-FDP. Furthermore, dependence on $\mathrm{pH}$ and temperature for product specificity was assessed by altering the reaction conditions. Moreover, we analyze the conformational changes during catalysis and the identification of putative key residues that take part in the catalytical process. The generated knowledge provides the basis for understanding the reaction mechanisms of ZS for further protein engineering studies.

\section{RESULTS AND DISCUSSION}

2.1. Biotransformation Assays and Product Identification of ZS with $(2 E, 6 E)-F D P$. The product spectrum of the reaction of $\mathrm{ZS}$ with the naturally occurring substrate $(2 E, 6 E)$-FDP was assessed by biotransformation assays based on the single-vial method reported by O'Maille et al. ${ }^{25}$ Similar to our previous report, ${ }^{24}$ the main product of the reaction was sesquiterpene $(+)$-zizaene (91.46\% abundance). Additionally, we identified $\beta$-acoradiene ( $8.54 \%$ abundance) as a side product (Figure 1), which is found in traces in the vetiver essential oil ${ }^{19}$ and is a deprotonated compound from the acorenyl cation, an intermediate in the biosynthesis of (+)-zizaene. ${ }^{26}$
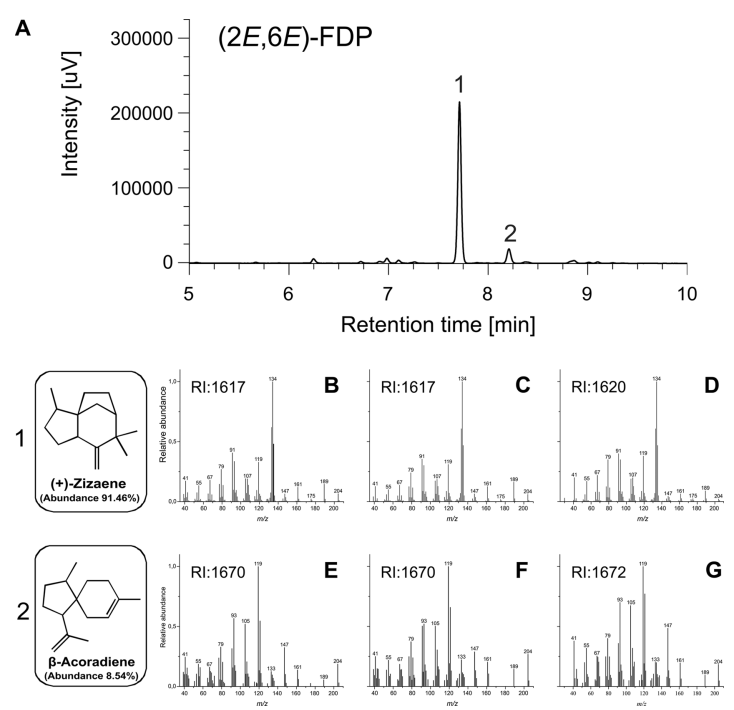

Figure 1. (A) Product spectrum of the biotransformation assay of $(2 E, 6 E)$-FDP with ZS by gas chromatography-mass spectroscopy (GC-MS). (+)-Zizaene: (B) mass spectrum from peak 1. (C) Mass spectrum of authentic (+)-zizaene from vetiver oil. (D) Mass spectrum of authentic (+)-zizaene from ref 27. $\beta$-Acoradiene: $(\mathrm{E})$ mass spectrum from peak 1. (F) mass spectrum of authentic $\beta$ acoradiene from vetiver oil. (G) Mass spectrum of authentic $\beta$ acoradiene from ref 28 .

2.2. Optimization of Reaction Conditions. The optimal temperature and $\mathrm{pH}$ of the reaction of $\mathrm{ZS}$ with $(2 E, 6 E)$-FDP was determined for the main product $(+)$-zizaene; thus, the optimal region for the reaction rate $\left(>1.6 \mu \mathrm{M} \mathrm{min}{ }^{-1}\right)$ was calculated between $\mathrm{pH} 7.33-7.65$ and temperature 34.15$38.10{ }^{\circ} \mathrm{C}$ (Figure $2 \mathrm{a}$ ). The medium reaction rate $(1.4-1.6 \mu \mathrm{M}$ $\min ^{-1}$ ) was determined between $\mathrm{pH} 7.0-7.8$ and 32.5-42.0 ${ }^{\circ} \mathrm{C}$ of temperature. Consequently, optimal reaction conditions were defined at $\mathrm{pH} 7.5$ and $36{ }^{\circ} \mathrm{C}$ for further tests. The activity of STC takes place in cytosol, ${ }^{29}$ which is characterized by $\mathrm{pH}$ 7.5. ${ }^{30}$ Therefore, optimal $\mathrm{pH}$ of $\mathrm{ZS}$ was found within the expected range and was similar to that for other reported STC. ${ }^{31-33}$ Activity of ZS was detected even between 21 and 42 ${ }^{\circ} \mathrm{C}$ at $\mathrm{pH}$ 7.0. Consequently, the broad temperature range for ZS activity allows the vetiver grass to produce (+)-zizaene under different climates. ${ }^{34}$

2.3. Analysis of Kinetic Parameters. A study for the ZS kinetic parameters was carried out under the determined optimal reaction conditions $\left(36{ }^{\circ} \mathrm{C}, \mathrm{pH} 7.5\right)$ with $0.1 \mu \mathrm{M}$ purified ZS and monitored in a range of $1-50 \mu \mathrm{M}(2 E, 6 E)$ FDP. Respective velocities were calculated by the product formation only for the main product: $(+)$-zizaene. Figure $2 \mathrm{~b}$ describes the kinetics of $\mathrm{ZS}$, where velocities increased from 1 to $5 \mu \mathrm{M}$ of $(2 E, 6 E)$-FDP with $V_{\max } 0.35 \mu \mathrm{M} \mathrm{min}{ }^{-1}, K_{\mathrm{M}} 0.88$ $\mu \mathrm{M}$, and $k_{\mathrm{cat}} / K_{\mathrm{M}} 6.71 \times 10^{4} \mathrm{M}^{-1} \mathrm{~s}^{-1}$. Consequently, the catalytic efficiency of ZS was higher under optimal conditions when compared with our previous report, ${ }^{24}$ which achieved $V_{\max } 0.32 \mu \mathrm{M} \mathrm{min}^{-1}, K_{\mathrm{M}} 1.11 \mu \mathrm{M}$, and $k_{\text {cat }} / K_{\mathrm{M}} 4.43 \times 10^{4} \mathrm{M}^{-1}$ 
A

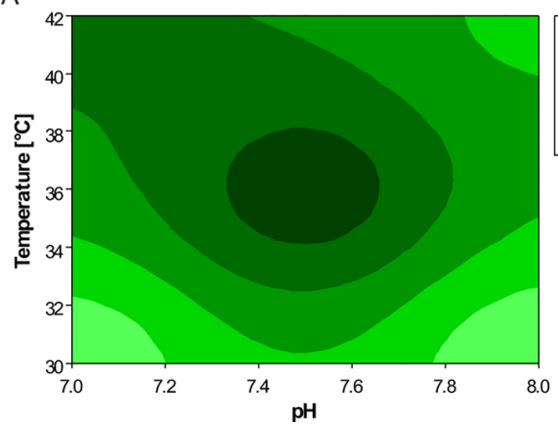

B

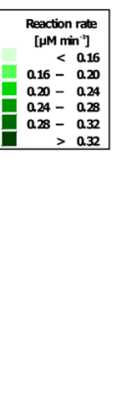

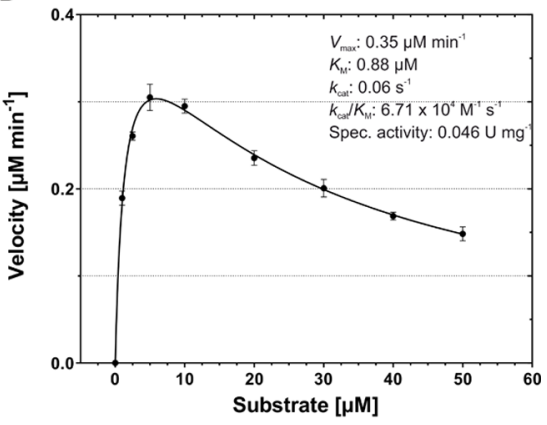

Figure 2. (A) Optimization of temperature and $\mathrm{pH}$ in the biotransformation of (2E,6E)-FDP with ZS. Variable of study corresponds to the reaction rate of zizaene. (B) Enzyme kinetics plot of ZS showing reaction velocities at increasing concentrations of (2E,6E)-FDP. Reaction velocities calculated from five measurements by a discontinuous assay method and performed in triplicates. Error bars represent standard deviation (SD) of three independent measurements.

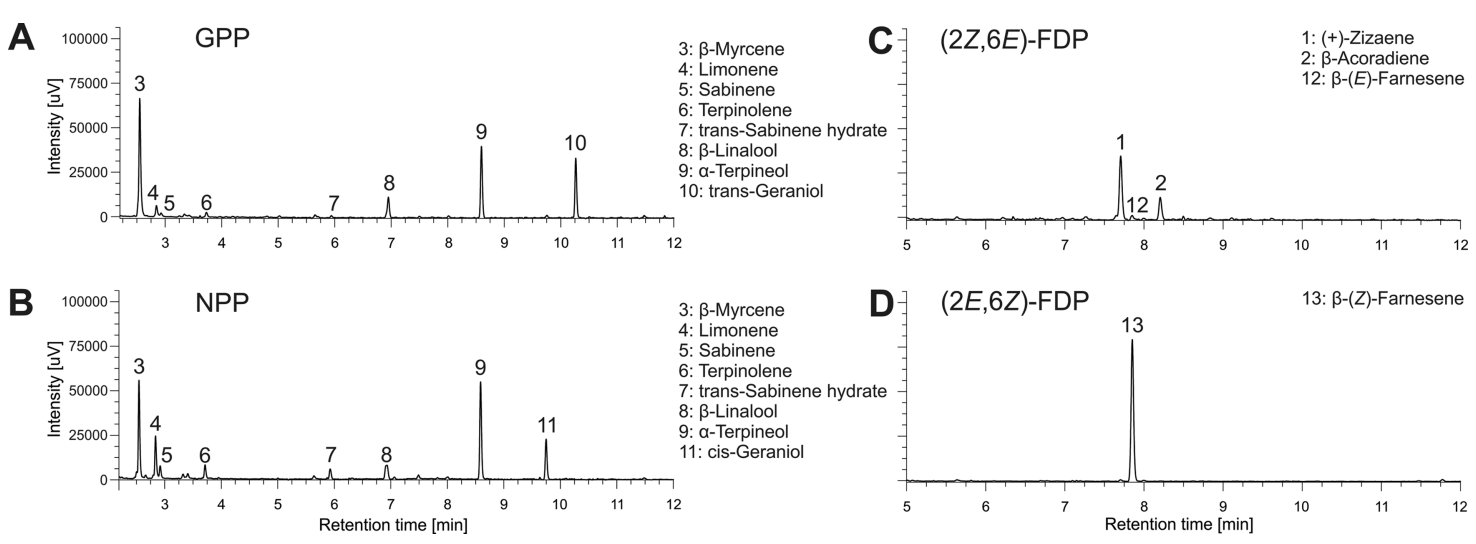

Figure 3. GC-MS analysis of the product spectrum of the reaction of ZS with alternative substrates. Monoterpene substrates: (A) GPP. (B) NPP. Sesquiterpene isomer substrates: (C) $(2 Z, 6 E)$-FDP. (D) (2E,6Z)-FDP. Mass spectra for each product can be found in Tables S1 and S2.

Table 1. Identification of the Product Spectrum Obtained from the Biotransformation of Monoterpene Substrates (GPP and NPP) with ZS

\begin{tabular}{|c|c|c|c|c|c|c|c|c|}
\hline \multirow[b]{2}{*}{ peak } & \multirow[b]{2}{*}{ compound } & \multicolumn{2}{|c|}{ abundance (\%) } & \multicolumn{2}{|c|}{ RI samples } & \multirow[b]{2}{*}{ RI literature } & \multirow[b]{2}{*}{ identification $^{a}$} & \multirow[b]{2}{*}{ references } \\
\hline & & GPP & NPP & GPP & NPP & & & \\
\hline 3 & $\beta$-myrcene & 40.32 & 26.93 & 1151 & 1151 & 1155 & $(a)(b)$ & 43 \\
\hline 4 & limonene & 4.2 & 12.68 & 1182 & 1182 & 1180 & (a)(b) & 44 \\
\hline 5 & sabinene & 1.45 & 3.72 & 1185 & 1185 & 1156 & $(a)(b)$ & 45 \\
\hline 6 & terpinolene & 1.71 & 3.73 & 1266 & 1266 & 1266 & (a)(b) & 46 \\
\hline 7 & trans-sabinene hydrate & 1.12 & 3.28 & 1440 & 1440 & 1447 & (a)(b) & 47 \\
\hline 8 & $\beta$-linalool & 8.21 & 7.28 & 1524 & 1524 & 1531 & $(a)(b)$ & 48 \\
\hline 9 & $\alpha$-terpineol & 23.87 & 29.63 & 1669 & 1669 & 1669 & $(a)(b)(c)$ & 49 \\
\hline 10 & trans-geraniol & 19.12 & & 1817 & & 1822 & (a)(b) & 50 \\
\hline 11 & cis-geraniol & & 12.75 & & 1772 & 1777 & $(a)(b)$ & 50 \\
\hline
\end{tabular}

${ }^{a}$ Identification of compounds: (a) Mass spectrum from the sample matches the library mass spectrum. (b) Retention index of sample matches the retention index in the literature. (c) Mass spectrum and the retention index of the sample matches the authentic standard; both run in the same GC-MS system. Mass spectrum of samples can be found in Supporting Information (SI), Table 1.

$\mathrm{s}^{-1}$. The difference between both studies was the increase in temperature to $36{ }^{\circ} \mathrm{C}$, which favored reaction rates and lowered $K_{\mathrm{M}}$. The low values of the obtained kinetic parameters were expected for plant enzymes from the secondary metabolism, because their products are not required for essential metabolic functions. ${ }^{30}$ Consequently, our results are in accordance with similar reported STC activities. ${ }^{35-38}$

In our previous report, ZS followed an apparent MichaelisMenten kinetics, ${ }^{24}$ although a slight decrease in velocity was observed from 30 to $40 \mu \mathrm{M}(2 E, 6 E)$-FDP. In optimal reaction conditions, ZS showed a decrease in velocities from 10 to 50 $\mu \mathrm{M}$ (2E,6E)-FDP (velocities of $0.29-0.15 \mu \mathrm{M} \mathrm{min}^{-1}$ ). Consequently, ZS kinetics follows a substrate inhibition model when the reaction is held at optimal conditions. Such kinetics were also reported for the recombinant patchoulol synthase $^{39}$ and ent-Copalyl diphosphate synthase (diterpene cyclase). Apparently, an excess of substrate binds to two different sites in the enzyme: the substrate binding site (aspartate-rich motif) and the active site, ${ }^{40}$ forming nonproductive binding (ESS). Moreover, the above-mentioned study demonstrated that the cofactor $\left(\mathrm{Mg}^{2+}\right)$ served also as an inhibitor at levels higher than $0.1 \mu \mathrm{M} \mathrm{MgCl}_{2}$. In the case of $\mathrm{ZS}$, 
Scheme 1. Proposed Reaction Mechanisms of ZS with Distinct $\mathrm{C}_{10}$ and $\mathrm{C}_{15}$ Substrates ${ }^{a}$
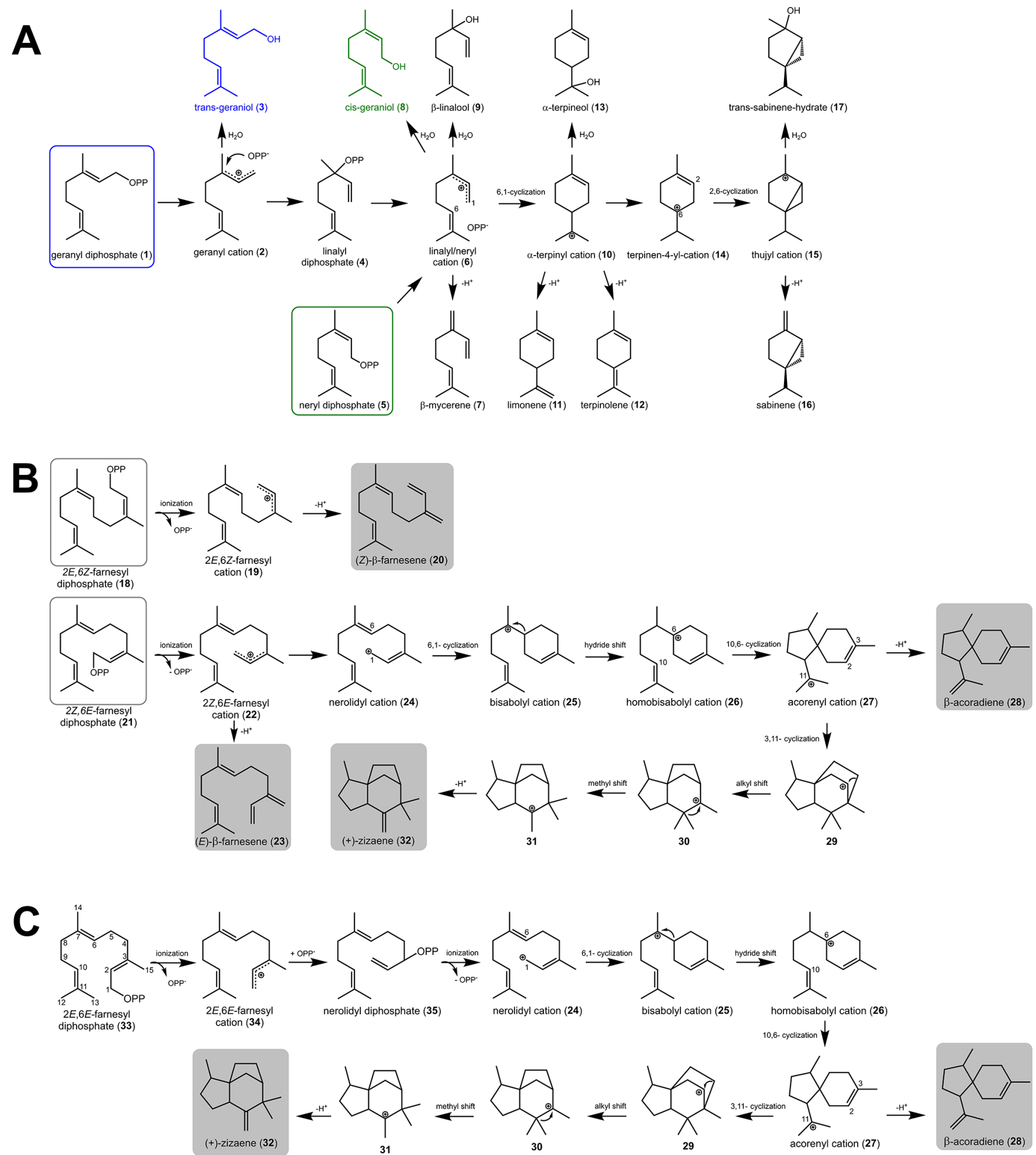

${ }^{a}$ (A) Reaction mechanism for monoterpene substrates GPP and NPP. Colors indicate unique products according to the substrate. The mechanism is modified from Alonso and Croteau. ${ }^{15}$ (B) Reaction mechanism from sesquiterpene substrate isomers (2E,6Z)-FDP and (2Z,6E)-FDP. (C) Reaction mechanism from the naturally occurring sesquiterpene substrate $(2 E, 6 E)$-FDP. Final products are highlighted in gray. Mechanisms are modified from Mercke et al. ${ }^{32}$ and Aaron et al. ${ }^{7}$

amounts higher than $10 \mathrm{mM} \mathrm{MgCl}_{2}$ proved also inhibition. Consequently, substrate inhibition plays a role in the regulation of terpene metabolism; hence, the levels of cofactors (divalent metal ions) are modulated by physical factors, such as light. ${ }^{40}$ Further studies are required to clarify whether physical factors or nutrient uptake regulate the levels of cofactors and khusimol biosynthesis in roots of Ch. zizanioides.

2.4. Reaction Mechanisms of $Z S$ with $C_{10}$ Substrates. To analyze the enzymatic versatility of $\mathrm{ZS}$, the alternative substrates $C_{10}, C_{15}$, and $C_{20}$ prenyl diphosphates were 
Table 2. Identification of the Product Spectrum Obtained from the Biotransformation of Sesquiterpene Substrates with ZS

\begin{tabular}{|c|c|c|c|c|c|c|c|}
\hline \multirow[t]{2}{*}{ alternative substrate } & \multirow[t]{2}{*}{ peak } & \multirow[t]{2}{*}{ compound } & \multirow[t]{2}{*}{ compoundabundance (\%) } & \multicolumn{2}{|c|}{ retention index } & \multirow[t]{2}{*}{ identification $^{a}$} & \multirow[t]{2}{*}{ references } \\
\hline & & & & sample & literature & & \\
\hline$(2 E, 6 Z)-F D P$ & 13 & $\beta$-(Z)-farnesene & 100 & 1621 & 1630 & $(a)(b)$ & 51 \\
\hline \multirow[t]{3}{*}{$(2 Z, 6 E)-\mathrm{FDP}$} & 1 & $(+)$-zizaene & 81.7 & 1617 & 1620 & $(a)(b)(c)$ & 27 \\
\hline & 12 & $\beta$-(E)-farnesene & 5.51 & 1651 & 1659 & $(\mathrm{a})(\mathrm{b})$ & 52 \\
\hline & 2 & $\beta$-acoradiene & 12.79 & 1670 & 1672 & $(a)(b)(c)$ & 28 \\
\hline
\end{tabular}

${ }^{a}$ Identification of compounds: (a) Mass spectrum from the sample matches the library mass spectrum. (b) Retention index of sample matches the retention index in the literature. (c) Mass spectrum and the retention index of the sample match those of terpene from the vetiver oil; both run in the same GC-MS system. The mass spectrum of samples can be found in SI, Table 2.
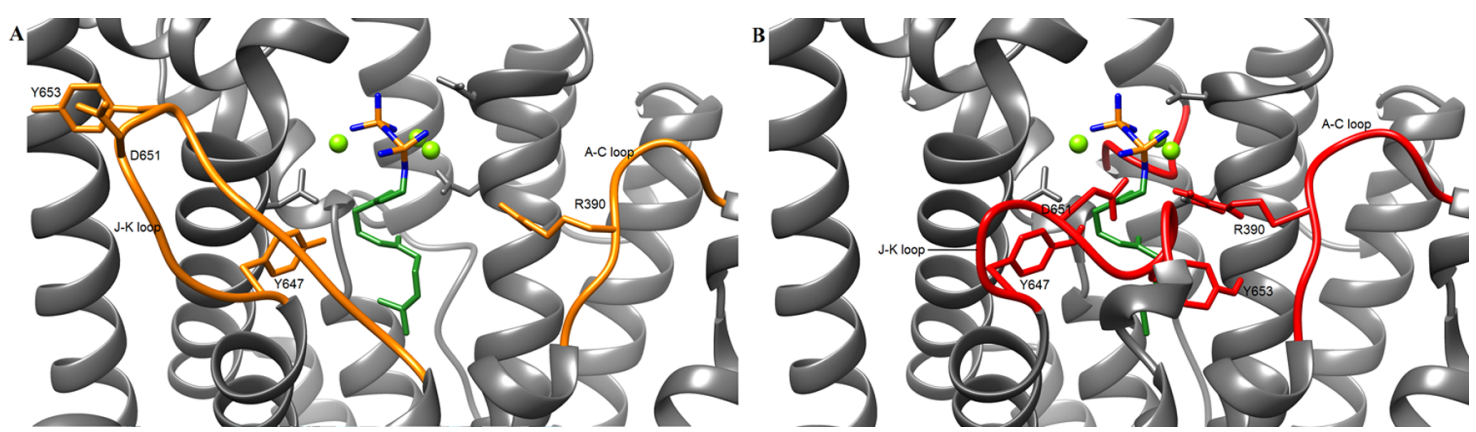

Figure 4. Structural homology models of the open and closed conformations of the ZS active site docked with (2E,6E)-FDP. (A) Open conformation of ZS shows the J-K and A-C loops in orange and $\mathrm{Mg}^{2+}$ divalent ions in green. (B) Closed conformation of ZS shows folding of the J$\mathrm{K}$ and $\mathrm{A}-\mathrm{C}$ loops in red. Putative relevant residues for capping the active site are labeled.

evaluated (Figure 3). ZS accepted both monoterpene precursors (NPP and GPP) and produced a mixture of cyclic and acyclic monoterpenes (Table 1). Product formation was catalyzed due to the activity of $\mathrm{ZS}$; hence, no products were observed in negative controls (reactions with alternative substrates without ZS). Accordingly, ZS was able to accept monoterpene substrates due to the large active cavity compared to that of the short $\mathrm{C}_{10}$ prenyl tail, as demonstrated by other STCs. ${ }^{32,41,42}$

As shown in the proposed reaction mechanisms for monoterpene substrates (Scheme 1a), GPP undergoes ionization to geranyl cation (2). On one side, it hydroxylates to trans-geraniol (3) and on the other, isomerizes to linalyl diphosphate (4) for further ionization to form linalyl/neryl cation (6). In contrast, NPP leads directly to neryl cation (6) after ionization and leads further to cis-geraniol (syn. Nerol) (8). As a result, both substrates converge into linalyl/neryl cation, leading to three paths: (1) deprotonation to the acyclic $\beta$-mycerene (7), (2) hydroxylation to $\beta$-linalool (9), and (3) 6,1-cyclization to $\alpha$-terpinyl cation (10), the precursor of cyclic monoterpenes. Further, both follow quenching by deprotonation to yield limonene (11) and terpinolene (12), water addition for $\alpha$-terpineol (13), and 2,6-ring closure to thujyl cation (15). Finally, sabinene (16) and trans-sabinene-hydrate (17) are formed.

As a consequence, product specificity of both substrates was low, generating eight monoterpenoids. GPP and NPP yielded as major products $\beta$-mycerene $(40.3 \%, 26.9 \%)$ and $\alpha$-terpineol $(23.8 \%, 29.6 \%)$, respectively, and geraniol isomers (GPP: trans-geraniol 19.1\% NPP: cis-geraniol 12.7\%). Interestingly, both substrates converted more than $50 \%$ to hydroxylated monoterpenes ( $\alpha$-terpineol, $\beta$-linalool, trans-sabinene hydrate, trans-geraniol, and cis-geraniol). Possibly, water molecules surrounding the active site of ZS are activated and assist the hydroxylation process. Such hydroxylation was demonstrated before, wherein a water molecule found in the active site of salvia monoterpene synthase participated in the water addition of $\alpha$-terpinyl cation to generate $\alpha$-terpineol. ${ }^{53}$

2.5. Reaction Mechanisms of $Z S$ with $C_{15}$ and $C_{20}$ Substrates. Assays with FDP isomers converted only to nonhydroxylated sesquiterpenes (Table 2), whereas geranylgeranyl diphosphate did not produce any products. It is known that STC do not accept $\mathrm{C}_{20}$ prenyl diphosphates substrates because the prenyl tail is too large to fit in the cavity of STC. ${ }^{17,54}$

The proposed reaction mechanism for isomer (2E,6Z)-FDP leads to $(2 E, 6 Z)$-farnesyl cation (19) after ionization and further premature quenching to form $(Z)-\beta$-farnesene (20) (Scheme 1b). Therefore, isomerization to nerolidyl diphosphate is not possible due to the $(2 E, 6 Z)$ stereochemistry of the prenyl tail. Possibly, the prenyl tail does not position correctly into the inner cavity of the active site and cannot undergo further rearrangements. Consequently, (2E,6Z)-FDP reaction resembles the functioning of farnesene synthases ${ }^{55,56}$ and showed the highest product specificity with $100 \%$ abundance of the main product in relation to all substrates tested.

Regarding (2Z,6E)-FDP, the proposed mechanism leads directly to $(2 Z, 6 E)$-farnesyl cation (22), after ionization of $\mathrm{PP}_{\mathrm{i}}$ (Scheme 1b). One path leads to $(E)-\beta$-farnesene $(23)(5.51 \%$ abundance) and most of the flux leads to nerolidyl cation (24) and further 6,1 ring closure to bisabolyl cation (25). After a hydride shift, a 10,6-cyclization leads to acorenyl cation (27). From here, two paths occur: one leads to $\beta$-acoradiene (26) ( $12.79 \%$ abundance) by deprotonation and the other leads to 3,11-cyclization to form a three ring carbocationic intermediate (29). The latter passes through a carbocation cascade with final deprotonation to the main product (+)-zizaene (32). Consequently, $(2 Z, 6 E)$-FDP shows a high product specificity for $(+)$-zizaene with an abundance of $81.7 \%$. Additionally, the low abundance of $(E)$ - $\beta$-farnesene suggests a premature exit of 
the $(2 Z, 6 E)$-farnesyl cation from the active site for further carbocation deprotonation.

2.6. Conformational Changes During Catalysis. Analysis of docking models in open and closed conformations shows the structural changes occurring during substrate binding. Most relevant is the closing of the J-K and A-C loops, wherein in the open conformation, they remain unfolded, allowing the entrance of molecules (Figure 4a). In the closed conformation, they fold to the active site (Figure $4 \mathrm{~b})$, acting as a lock to create a hydrophobic environment suitable for carbocation cascades. Residue D651 from the J-K loop is directed toward the binding site and possibly participates in the coordination of divalent $\mathrm{Mg}^{2+}$ ions. Additionally, Y653 folds toward the prenyl tail and is involved in its stabilization. Contrary to Y653, Y647 does not suffer major positioning because it is already near to the active site. Subsequently, the R390 from the A-C loop folds toward the $\mathrm{PP}_{\mathrm{i}}$, completing the capping of the active site.

According to the docking model in the closed conformation, $\mathrm{Mg}_{\mathrm{A}}{ }^{2+}$ and $\mathrm{Mg}_{\mathrm{C}}{ }^{2+}$ ions bind to the $\mathrm{D}^{427}$ DIYD ${ }^{431}$ motif, and $\mathrm{Mg}_{\mathrm{B}}{ }^{2+}$ ion, to the $\mathrm{ND}^{572} \mathrm{IASHE}^{577}$ motif (Figure 5). Divalent

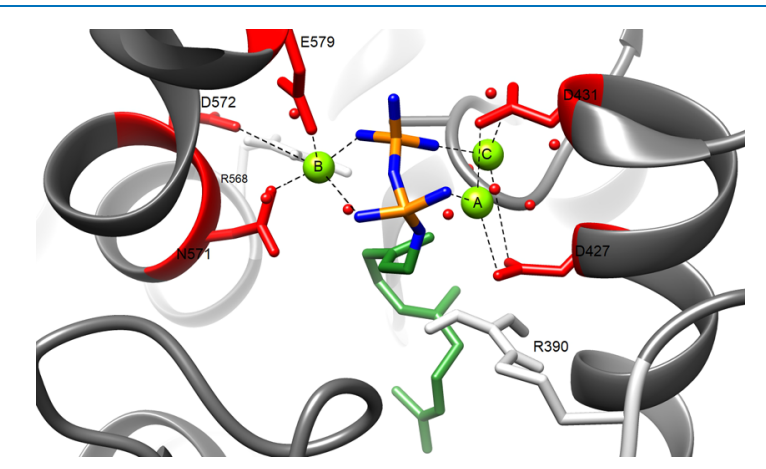

Figure 5. Docking model showing the interactions that occur during binding of $(2 E, 6 E)$-FDP in the active site of ZS. Metal coordination interactions are shown between D572, E579, D427, and D431 residues (red) from the aspartate-rich motifs with the $\mathrm{Mg}^{2+}$ divalent ions (light green) and water molecules (red spheres). Putative hydrogen bond interactions shown between R390 and R568 (light gray) with the phosphate moiety of FDP (blue/orange).

ions coordinate the metal binding of $\mathrm{PP}_{\mathrm{i}}$ from $(2 E, 6 E)$-FDP accompanied by hydrogen bond interactions, and water molecules occupy the surrounding area, binding to the $\mathrm{Mg}^{2+}$ ions. Furthermore, the prenyl tail is located in the interior of the active site (Figure 6a), surrounded by V423 and D651 residues and the aromatic residues Y647, Y653, W399, and F420, which in turn, stabilize the complex in the closed active site conformation.

2.7. Reaction Mechanism of ZS with $(2 E, 6 E)$-FDP. The proposed reaction mechanism undergoes ionization of (2E,6E)-FDP, whereas the $\mathrm{PP}_{\mathrm{i}}$ group is cleaved and the $(2 E, 6 E)$-farnesyl cation is formed (Figure 6b). The D651 assists the FDP isomerization by sequestering the farnesyl cation (34) at $C_{1}$, which in turn captures further the $\mathrm{PP}_{\mathrm{i}}$ moiety, leading to nerolidyl diphosphate (35) (Scheme 1c). Likewise, the positively charged residues R390 and R568 sequester the $\mathrm{PP}_{\mathrm{i}}$ anion and pull it apart from the prenyl tail, as reported by Bohlmann et al. ${ }^{6}$ After ionization of the diphosphate isomer, nerolidyl cation (4) is formed and V423 together with Y653 assists the positioning of the carbocation inside the inner cavity.

Furthermore, $C_{1}$ bends toward $C_{6}$, promoting the 6,1cyclization, leading to the bisabolyl cation (25). The $\mathrm{C}_{6}$ positive charge could be stabilized either by Y653 or W399 through $\pi$-cation interactions, and after an alkyl shift, the homobisabolyl cation (26) is formed. Further cyclizations and rearrangements could be concerted by aromatic residues positioned in the interior of the cavity (F639, W399, and F420), as shown in Figure 6b. Thereafter, electrophilic attack of $\mathrm{C}_{10}$ of homobisabolyl cation leads to the 10,6-cyclization to form the double-ring acorenyl cation (27), which branches into two paths: deprotonation to form $\beta$-acoradiene (28) and 3,11 ring closure that leads to a triple ring intermediate (29). Further carbocation rearrangements include an alkyl shift (30), methyl shift (31), and deprotonation to form the main product (+)-zizaene (32). Eventually, W399 functions as a proton acceptor in the final deprotonation reaction. ${ }^{8}$

The latter reaction mechanism follows a related biogenic origin for sesquiterpenes derived from the bisabolyl cation, a primary intermediate for diverse sesquiterpene families: bisabolene, curcumene, $\beta$-acoradiene, zizaene, cedrene, duprezianene, and sesquithuriferol. ${ }^{26} \mathrm{ZS}$ is able to undergo successfully the 10,6-ring closure that leads to acorenyl cation. Nevertheless, the complex 3,11-cyclization is not fully processed; thus, the side product $\beta$-acoradiene is formed. Although the 2,11-cyclization could be another favorable path,
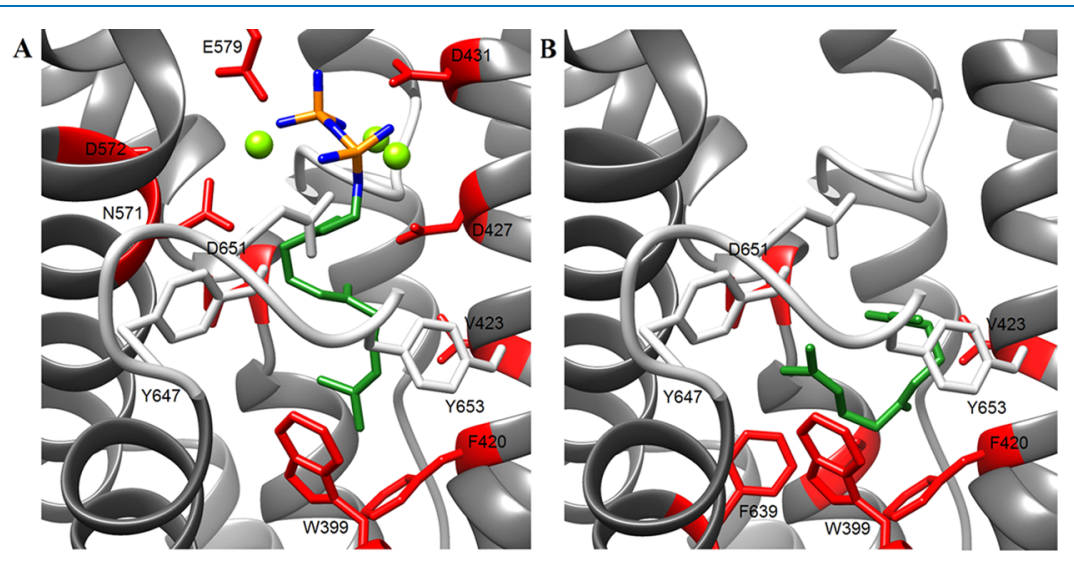

Figure 6. Proposed interacting residues of ZS with (2E,6E)-FDP (A) and (2E,6E)-farnesyl cation (B) during binding and isomerization of FDP based on docking modeling. Putative interacting residues from helices are marked in red, and residues from J-K loop are marked in light gray. Phosphate moiety of FDP is shown in blue/orange, prenyl tail/farnesyl cation in dark green, and $\mathrm{Mg}^{2+}$ divalent ions in light green. 


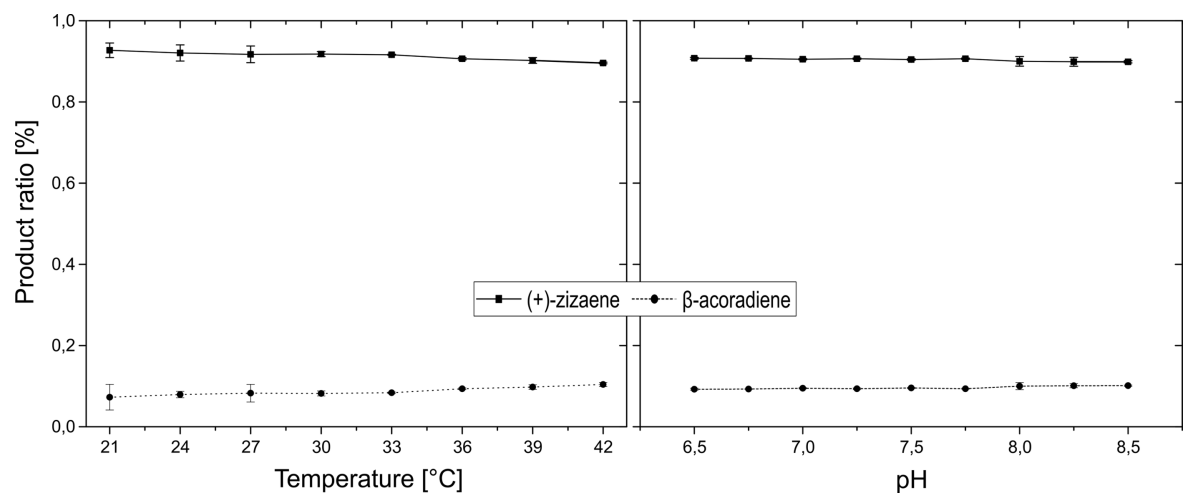

Figure 7. Study of the dependency of temperature and $\mathrm{pH}$ to the product ratio of (+)-zizaene ( $\mathbf{\square})$ and $\beta$-acoradiene $(2 E, 6 E)$-FDP with ZS. Error bars represent the SD of three independent measurements.

it seems at this point that ZS is prone to early quenching and deprotonation occurs. However, most of the flux successfully undergoes 3,11-cyclization and, after different rearrangements, (+)-zizaene is formed with a $91.46 \%$ abundance, resulting in high product specificity.

It is known that aromatic residues in the active site are able to stabilize the partial positive charges of carbocation intermediates either by charge-quadrupole or cation $-\pi$ interactions. ${ }^{1}$ Accordingly, plant STC comprise conserved aromatic residues in the active cavity, ${ }^{8}$ such as Y647, Y653, and W399, found in both ZS and TEAS. Interestingly, ZS includes two additional aromatic residues (F420 and F639), which are crucial for the stabilization of the complex carbocations and cyclizations in the biosynthesis of (+)-zizaene. Additionally, the active cavity volume of ZS was calculated in $367.7 \AA^{3}$, which could be considered tight when compared with other STC cavity volumes that are over $415 \AA^{3} .^{57,58}$ This suggests that the ZS cavity does not have enough space to allow alternative conformations of the prenyl tail, which results in an almost unique reaction pathway and high product specificity.

2.8. Effect of Temperature and $\mathrm{pH}$ on Product Specificity. The complex mechanisms of STC are affected by reaction conditions, such as $\mathrm{pH}$ and temperature, which regulate the product ratio (proportion of generated terpenoids), as demonstrated by others. ${ }^{12,18}$ To evaluate the $\mathrm{pH}$ and temperature effect on product specificity, an analysis was conducted on the product spectrum of $\mathrm{ZS}$ with the substrate (2E,6E)-FDP by the single-vial method assay. ${ }^{25}$ Accordingly, the temperature was evaluated from 21 to $42{ }^{\circ} \mathrm{C}$ at $\mathrm{pH} 7.5$ and $\mathrm{pH}$ was tested from $\mathrm{pH} 6.5$ to 8.5 at $36{ }^{\circ} \mathrm{C}$. In the case of temperature, a minor decrease in the product ratio for the main product $(+)$-zizaene was observed at increasing temperatures (Figure 7); hence, it shifted from 92.73 to $89.6 \%$ in temperatures from 21 to $42{ }^{\circ} \mathrm{C}$. On the contrary, the side product $\beta$-acoradiene showed an increase from 7.27 to $10.4 \%$ at increasing temperatures $\left(21-42{ }^{\circ} \mathrm{C}\right)$.

It has been demonstrated previously that temperature has an effect on product specificity for other STCs; ${ }^{16,18}$ thus, 5-epiaristolochene synthase (TEAS) showed a trend in which higher temperatures decreased the production of the main product from 87.6 to $66.2 \%$ ( $21.4 \%$ shift). It was proposed that higher temperatures increased the protein motion and destabilized the J-K loop, allowing the exit of intermediates from the active site prior to cyclization. ${ }^{18}$ On the contrary, the slight shift observed in the product ratio of ZS (3.13\%) suggests a strong global conformation of the enzyme to endure energetic fluctuations. Moreover, it suggests an efficient binding of the J-K and A-C loops to the binding site, which seals the active site from external solvents, creating a hydrophobic environment. According to our model (Figure 4), distinct residues from the surrounding loops could be responsible for the binding efficiency, as they change their position drastically from an open to a closed conformation. The $\mathrm{D} 651$ residue from the $\mathrm{J}-\mathrm{K}$ loop points to be critical in binding efficiency, as it is positioned strategically in the closed conformation and possibly participates in $\mathrm{Mg}^{2+}$ coordination and farnesyl cation capture during FDP isomerization. In addition, aromatic residues Y647 and Y653 seem also relevant because they are able to bind and stabilize the prenyl tail.

Concerning $\mathrm{pH}$ experiments, it could be shown that $\mathrm{pH}$ had less effect than temperature on the product ratio (Figure 7 ), since (+)-zizaene levels decreased slightly from 90.75 to $89.88 \%$ in the studied $\mathrm{pH}$ range $(6.5-8.5)$. Similar to temperature, the alternative product $\beta$-acoradiene tends to increase its product ratio from 9.25 to $10.12 \%$ at higher $\mathrm{pH}$ values. Distinct STCs have shown product ratio dependence on $\mathrm{pH}^{12,16,59}$ because it affects the reaction solvent and, in turn, distinct reactions such as hydride shifts, deprotonations, and hydroxylations. A relevant mechanism for $\mathrm{pH}$ dependence was proposed for the fungal STC Cop4 from Coprinus cinereus, where basic residues (histidines) in the $\mathrm{H}-1 \alpha$ loop showed susceptibility to $\mathrm{pH}$ changes due to net charge shifts. ${ }^{60}$ As a result, this decreased the binding efficiency of the $\mathrm{H}-1 \alpha$ loop to the binding pocket, allowing early quenching. In the case of $\mathrm{ZS}$, the H-1 $\alpha$ loop ( $\mathrm{L}^{494}$ IDAAKCY $\left.{ }^{501}\right)$, J-K loop $\left(\mathrm{Y}^{647} \mathrm{NGVDLYTI}^{655}\right)$, and A-C loop $\left(\mathrm{L}^{386} \mathrm{TFARDR}^{392}\right)$ are composed mostly of hydrophobic and neutral residues. Because of their polarity, they remain unaffected at the tested $\mathrm{pH}$ and are able to seal efficiently the binding pocket, creating a hermetic hydrophobic cavity.

\section{CONCLUDING REMARKS}

The described work leads to new insights into the characteristics, product spectrum, and reaction mechanisms of the recombinant ZS. A deeper study of the enzyme kinetics reveals that ZS follows a substrate inhibition model that has been observed in other terpene cyclases as a putative regulation mechanism for the biosynthesis of terpenoids.

Furthermore, analysis with alternative substrates shows low product specificity of $\mathrm{ZS}$ when assayed with $\mathrm{C}_{10}$ substrates but high product specificity when converting $C_{15}$ isoprenoid diphosphate substrates. The proposed reaction mechanisms reveal critical carbocations and cyclizations through the 
biosynthesis of the generated terpenoids. Moreover, the conformational changes during catalysis were analyzed and putative residues were identified involved in the efficient capping of the active site. Our results provide new insights into the complex reaction mechanisms of $\mathrm{ZS}$, pointing to further studies that require an interdisciplinary approach concerning molecular biology, enzymology, and protein engineering.

\section{MATERIALS AND METHODS}

4.1. Chemicals. Monoterpene substrates GPP, NPP, sesquiterpene substrate $(2 E, 6 E)$-FDP, terpene standards, and additional chemicals were purchased from Sigma-Aldrich. FDP isomers (2E,6Z)-FDP and (2Z,6E)-FDP were chemically synthesized according to Frister. ${ }^{39}$ Vetiver oil from Haiti was kindly provided by Symrise.

4.2. Strain and Cultivation. Expression vector harboring the recombinant fused SUMO zizaene synthase gene used for enzyme production corresponds to the pETSUMO::ZIZ(co) (GenBank: KP231534) and was transformed into E. coli strain B121 (DE3) from Novagen, as described in Hartwig. ${ }^{39}$ Cultivation was carried out in a $2 \mathrm{~L}$ stirred-tank bioreactor (Biostat-B Sartorius, Germany) with $2 \mathrm{~L}$ of defined medium ${ }^{61}$ supplemented with $20 \%$ glucose as the sole carbon source and $50 \mu \mathrm{g} \mathrm{mL}^{-1}$ kanamycin. Inoculation was performed to obtain an initial $\mathrm{OD}_{600}$ of 0.1 rel. $\mathrm{AU}$ and the bioreactor controller was set to $37{ }^{\circ} \mathrm{C}, \mathrm{pH} 7.5$ and controlled with $1 \mathrm{M} \mathrm{NaOH}$, initial stirring at $300 \mathrm{rpm}$, and air gassing at $0.5 \mathrm{vvm}$. The dissolved oxygen $\left(\mathrm{pO}_{2}\right)$ was monitored by a polygraphic $\mathrm{pO}_{2}$ sensor, set above $30 \%$ saturation, and controlled in cascade mode with the following settings: (1) stirring and (2) pure oxygen gassing. Induction of ZS was initiated when the culture reached $\mathrm{OD}_{600} 0.7$ rel. AU. Thereafter, the temperature was lowered to $20{ }^{\circ} \mathrm{C}$ and $0.5 \mathrm{mM}$ isopropyl- $\beta$-D-thiogalactoside was added. The induction stage was carried out for $24 \mathrm{~h}$, thereafter the culture broth was centrifuged for $20 \mathrm{~min}(10000$ $\times g$ at $4{ }^{\circ} \mathrm{C}$ ) and the pellet was stored at $-20{ }^{\circ} \mathrm{C}$ until further use.

4.3. Enzyme Purification. Cells were resuspended at a concentration of $50 \mathrm{mg}$ of fresh weight per $\mathrm{mL}$ with binding buffer (50 mM 3-(N-morpholino) propane sulphonic acid (MOPS), pH 7.5, $150 \mathrm{mM} \mathrm{NaCl}, 10 \mathrm{mM} \mathrm{MgCl}, 10 \mathrm{mM}$ imidazole) and then cell disrupted by ultrasonication (Sartorius Labsonic, Germany) using the following parameters: 0.6 s cycle, $100 \%$ amplitude. After centrifugation, soluble protein fractions were filtered through $0.2 \mu \mathrm{m}$ polyethersulfone syringe filters. Enzyme purification was carried out by immobilized metal affinity chromatography (IMAC) through an ÄKTA Pure FPLC system (GE Healthcare), whereas clarified soluble fractions were applied to a HiPrep IMAC FF 16/10 $20 \mathrm{~mL}$ column (GE Healthcare) decorated with $\mathrm{Ni}^{2+}$ ions. After a proper column wash, the enzyme was eluted with elution buffer (50 mM MOPS, pH 7.5, $150 \mathrm{mM} \mathrm{NaCl}, 10 \mathrm{mM}$ $\mathrm{MgCl}_{2}, 500 \mathrm{mM}$ imidazole). Purified fractions were pooled into a vivaspin $2010-\mathrm{kDa}$ cut ultrafiltration tubes and the buffer was exchanged to STC storage buffer (50 mM MOPS, $\mathrm{pH} 7.5,1 \mathrm{mM}$ dithiothreitol (DTT), $10 \mathrm{mM} \mathrm{MgCl} 2,10 \%$ (v/ v) glycerol) and stored at $-20{ }^{\circ} \mathrm{C}$.

4.4. Biotransformation Assay. The catalytical reaction was performed following a modified single-vial assay method from O'Maille et al. ${ }^{25}$ consisting of reactions of $1 \mathrm{~mL}$ with activity buffer (50 mM MOPS, $1 \mathrm{mM} \mathrm{DTT,} 10 \mathrm{mM} \mathrm{MgCl}$, $10 \%(\mathrm{v} / \mathrm{v})$ glycerol) at $\mathrm{pH} 7.5,5 \mu \mathrm{M}(2 \mathrm{E}, 6 \mathrm{E})$-FDP, and 0.1 $\mu \mathrm{M}$ purified ZS. Reaction components were gently mixed in 8
$\mathrm{mL}$ glass vials and incubated at $30{ }^{\circ} \mathrm{C}$ in a water bath for 10 min. Reactions were stopped and products extracted by adding $250 \mu \mathrm{L}$ of pentane and vigorously vortexed for $60 \mathrm{~s}$. Vials were centrifuged for $10 \mathrm{~min}(4400 \times g$, room temperature), and the organic phase was transferred to $1.5 \mathrm{~mL} \mathrm{GC}$ vials for further measurements.

4.5. Gas Chromatography Analytics. Quantitative measurements of terpene products were performed by gas chromatography- flame ionization detector (GC-FID) with a GC-2010 plus GC system (Shimadzu, Japan) coupled to a flame ionization detector. Organic phase samples of $2 \mu \mathrm{L}$ were injected via an autosampler under a splitless mode (injector temperature of $240{ }^{\circ} \mathrm{C}$ ), and separation was carried out on a Zebron ZB-Wax Plus column (30 m length, $0.25 \mathrm{~mm}$ i.d., 0.25 $\mu \mathrm{m}$ film thickness) (Phenomenex). The oven temperature program was set to $40{ }^{\circ} \mathrm{C}$ for $20 \mathrm{~s}$, then raised to $200{ }^{\circ} \mathrm{C}(10$ $\left.{ }^{\circ} \mathrm{C} \mathrm{min}^{-1}\right)$ and $0.5 \mathrm{~min}$ hold, and then raised to $230{ }^{\circ} \mathrm{C}\left(30^{\circ} \mathrm{C}\right.$ $\min ^{-1}$ ) and 2 min hold. The FID was heated to $300^{\circ} \mathrm{C}$. Due to the lack of $(+)$-zizaene and $\beta$-acoradiene standards, quantification was calculated with a calibration curve of $\alpha$-cedrene standard, which has an equivalent mass $(204 \mathrm{~m} / z)$, as demonstrated previously. ${ }^{24}$

Reaction products were identified by GC-MS with a 7890B GC system (Agilent) coupled to an Agilent 5977A mass selective detector and equipped with a VF-WAXms capillary column $(30 \mathrm{~m} \times 0.25 \mathrm{~mm}$ i.d. $\times 0.25 \mu \mathrm{m})(\mathrm{J} \& \mathrm{~W}$ Scientific $)$. The transfer line and ion source temperature were set at 230 ${ }^{\circ} \mathrm{C}$ and the quadrupole at $150{ }^{\circ} \mathrm{C}$. The ionization energy was set at $70.0 \mathrm{eV}$, and the scan range, from 33 to $300 \mathrm{~m} / z$. Samples of $0.5 \mu \mathrm{L}$ were injected into the device by the oncolumn mode, using helium 5.0 as the carrier gas with a constant gas flow of $1 \mathrm{~mL} \mathrm{~min}^{-1}$. The oven temperature program was set to $40{ }^{\circ} \mathrm{C}$ for $3 \mathrm{~min}$ and then raised to $230{ }^{\circ} \mathrm{C}$ $\left(10{ }^{\circ} \mathrm{C} \mathrm{min}^{-1}\right)$ and a $10 \mathrm{~min}$ hold. Mass spectra data were analyzed with MassHunter Qualitative Analysis 7.0 (Agilent) and retention indices (RI) calculated according to van Den Dool and $\mathrm{Kratz}^{62}$ by an alkane standard solution $\left(\mathrm{C}_{8}-\mathrm{C}_{30}\right)$. For product identification, mass spectra and RI of samples were compared to those of others available in the mass spectral database NIST 14, literature references, terpenes from the vetiver oil of Ch. zizanioides, and/or authentic standards.

4.6. Optimization of the Reaction Conditions. The reaction conditions of the biotransformation assay of $(2 E, 6 E)$ FDP with ZS were analyzed using a two-level factorial experimental design with the reaction rate of $(+)$-zizaene as the study variable. Analyzed factors included temperature and $\mathrm{pH}$, each at two levels $\left(30{ }^{\circ} \mathrm{C} / \mathrm{pH} 7,42{ }^{\circ} \mathrm{C} / \mathrm{pH} 7,30^{\circ} \mathrm{C} / \mathrm{pH} 8\right.$, and $\left.42{ }^{\circ} \mathrm{C} / \mathrm{pH} 8\right)$ and one central point $\left(36{ }^{\circ} \mathrm{C} / \mathrm{pH} 7.5\right)$. Reactions for each treatment were carried out in $6 \mathrm{~mL}$ of master reaction solutions of activity buffer (Section 2.4) with 5 $\mu \mathrm{M}(2 E, 6 E)$-FDP and $0.1 \mu \mathrm{M}$ purified $\mathrm{ZS}$ in $8 \mathrm{~mL}$ glass vials. Master solutions were aliquoted rapidly into five $1 \mathrm{~mL}$ fractions in $8 \mathrm{~mL}$ glass vials and incubated in a water bath with the corresponding temperature for $2,4,6,8$, and $10 \mathrm{~min}$. Immediately after incubation, $250 \mu \mathrm{L}$ of iso-octane was promptly added and the reaction was quenched and products extracted by vigorous shaking. The organic phase was transferred to GC vials after centrifugation, and products were quantified by GC-FID. Each reaction condition was held in triplicates, and the reaction rate $\left(\mu \mathrm{M} \mathrm{min}{ }^{-1}\right)$ of $(+)$-zizaene was calculated from the average slope, obtained by linear regression. 
4.7. Enzyme Kinetics Parameters. Kinetical parameters of $\mathrm{ZS}$ were determined using the optimal reaction conditions $\left(36{ }^{\circ} \mathrm{C}, \mathrm{pH} 7.5\right)$ with increasing concentrations of the ubiquitous substrate $(2 E, 6 E)$-FDP $(1-50 \mu \mathrm{M})$ and $0.1 \mu \mathrm{M}$ purified ZS. Reactions proceeded as shown in Section 2.6, with the corresponding concentration of $(2 E, 6 E)$-FDP and (+)-zizaene quantified by GC-FID. Kinetic parameters were calculated from the velocities, which corresponded to the reaction rate $\left(\mu \mathrm{M} \mathrm{min}{ }^{-1}\right)$ of the main product $(+)$-zizaene. Data was fitted to the substrate inhibition model (eq 1), ${ }^{63}$ using the enzyme kinetics substrate inhibition module from GraphPad Prism 7 software (GraphPad).

$$
v=\frac{V_{\max }[S]}{K_{M}+[S]\left(1+\frac{[S]}{K_{\mathrm{i}}}\right)}
$$

4.8. Alternative Substrates. Product profiles of monoterpenes substrates GPP/NPP and sesquiterpene substrate isomers $(2 E, 6 Z)$-FDP and $(2 Z, 6 E)$-FDP were determined by biotransformation assays with ZS. Reactions were performed at $36{ }^{\circ} \mathrm{C}$ and $\mathrm{pH} 7.5$ with $5 \mu \mathrm{M}$ alternative substrate and $0.1 \mu \mathrm{M}$ purified ZS. Negative controls were carried out by reactions with alternative substrates without ZS. Furthermore, reactions were carried out according to the method described in Section 2.5. Identification of the generated products was performed by GC-FID and GC-MS, as described in Section 2.6.

4.9. Temperature and $\mathrm{pH}$ Dependency in Product Specificity. The product ratio of $(+)$-zizaene and $\beta$ acoradiene was assessed through varying temperatures and $\mathrm{pH}$ by the biotransformation assay with $5 \mu \mathrm{M}(2 E, 6 E)$-FDP and $0.1 \mu \mathrm{M}$ purified $\mathrm{ZS}$. Temperature dependence was studied between 21 and $42{ }^{\circ} \mathrm{C}$ at $\mathrm{pH} 7.5$, and $\mathrm{pH}$ dependency, in the range of $6.5-8.5 \mathrm{pH}$ at $36^{\circ} \mathrm{C}$. The biotransformation assay was performed as explained in Section 2.6, and sesquiterpenes were quantified by GC-FID. The product ratio was calculated as the amount of $(+)$-zizaene or $\beta$-acoradiene divided by the total amount of both.

4.10. Homology and Docking Modeling. Tridimensional structures of ZS were modeled using as templates the crystal structures of 5-epi-aristolochene synthase (TEAS) from Nicotiana tabacum, reported by Starks et al. ${ }^{8}$ The ZS open conformation model was built with the unliganded TEAS structure (PDB 5EAS, chain A, 32.4\% identity) and the closed conformation with the TEAS structure liganded with $3 \mathrm{Mg}^{2+}$ and FHP (PDB 5EAT, chain A, 31.9\% identity). For constructing the homology models, the SWISS-MODEL homology-modeling tool ${ }^{64}$ was used together with the $\mathrm{ZS}$ sequence (GenBank: KP231534) and the aforementioned templates.

Furthermore, molecular dockings of $(2 E, 6 E)$-FDP and (2E,6E)-farnesyl cation with the $\mathrm{ZS}$ model in closed conformation were carried out using the AutoDockTools suite 1.5.6. (The Scripps Research Institute). ${ }^{65}$ For this, preparation of the $\mathrm{ZS}$ receptor file involved the elimination of water molecules, adding and merging of hydrogen atoms, and adding Gasteiger charges. The grid was programmed as follows: grid box $(60 \times 60 \times 100)$ with default grid spacing $(0.375 \AA)$ that covered the active site, map types set directly including $\mathrm{Mg}^{2+}$ to the list, and a grid parameter file computed by AutoGrid 4.0. Docking settings included 25 GA runs, Lamarckian genetic algorithm for output, and AutoDock $4.0^{65}$ used for the generation of the docking parameter file. Docking conformations of both substrates presenting low binding energy were selected, and metal interactions occurring in the binding site were analyzed by the metal geometry tool from UCSF Chimera 1.11.2 (University of California). ${ }^{66}$ The activesite cavity volume of ZS was measured by the computer atlas of surface topology of proteins (CASTp) version 3.0. ${ }^{67}$ Structural model images were rendered by the program UCSF Chimera. $^{66}$

\section{ASSOCIATED CONTENT}

\section{Supporting Information}

The Supporting Information is available free of charge on the ACS Publications website at DOI: 10.1021/acsomega.9b00242.

Mass spectra of the identified terpene products from the alternative substrates (Tables S1 and S2) (PDF)

\section{AUTHOR INFORMATION}

\section{Corresponding Author}

*E-mail: beutel@iftc.uni-hannover.de. Phone: +49 511762 2867. Fax: +49511 7623004.

ORCID $\odot$

Sascha Beutel: 0000-0002-0983-9748

Funding

This work was supported by the PINN program from the Ministry of Science, Technology and Telecommunications of Costa Rica (MICITT). The publication of this article was funded by the Open Access Fund of the Leibniz Universität Hannover.

\section{Notes}

The authors declare no competing financial interest.

\section{ACKNOWLEDGMENTS}

We are grateful for the assistance provided for the product identification by Dipl. Daniel Sandner and Dr Ulrich Krings from the Institute of Food Chemistry at the Leibniz Hannover University.

\section{REFERENCES}

(1) Christianson, D. W. Structural Biology and Chemistry of the Terpenoid Cyclases. Chem. Rev. 2006, 106, 3412-3442.

(2) Merfort, I. Review of the analytical techniques for sesquiterpenes and sesquiterpene lactones. J. Chromatogr. A 2002, 967, 115-130.

(3) Cane, D. E. Isoprenoid Biosynthesis. Stereochemistry of the Cyclization of Allylic Pyrophosphates. Acc. Chem. Res. 1985, 18, 220226.

(4) Chen, F.; Tholl, D.; Bohlmann, J.; Pichersky, E. The family of terpene synthases in plants: a mid-size family of genes for specialized metabolism that is highly diversified throughout the kingdom. Plant $J$. 2011, 66, 212-229.

(5) Wendt, K. U.; Schulz, G. E. Isoprenoid biosynthesis: manifold chemistry catalyzed by similar enzymes. Structure 1998, 6, 127-133.

(6) Bohlmann, J.; Meyer-Gauen, G.; Croteau, R. Plant terpenoid synthases: Molecular biology and phylogenetic analysis. Proc. Natl. Acad. Sci. U.S.A. 1998, 95, 4126-4133.

(7) Aaron, J. A.; Lin, X.; Cane, D. E.; Christianson, D. W. Structure of epi-isozizaene synthase from Streptomyces coelicolor A3(2), a platform for new terpenoid cyclization templates. Biochemistry 2010, 49, 1787-1797.

(8) Starks, C. M.; Back, K.; Chappell, J.; Noel, J. P. Structural Basis for Cyclic Terpene Biosynthesis by Tobacco 5-Epi-Aristolochene Synthase. Science 1997, 277, 1815-1820. 
(9) Tarshis, L. C.; Yan, M.; Poulter, C. D.; Sacchettini, J. C. Crystal Structure of Recombinant Farnesyl Diphosphate Synthase at 2.6- $\AA$ Resolution. Biochemistry 1994, 33, 10871-10877.

(10) Salmon, M.; Laurendon, C.; Vardakou, M.; Cheema, J.; Defernez, M.; Green, S.; Faraldos, J. A.; O’Maille, P. E. Emergence of terpene cyclization in Artemisia annua. Nat. Commun. 2015, 6, No. 6143 .

(11) Degenhardt, J.; Köllner, T. G.; Gershenzon, J. Monoterpene and sesquiterpene synthases and the origin of terpene skeletal diversity in plants. Phytochemistry 2009, 70, 1621-1637.

(12) Miller, D. J.; Allemann, R. K. Sesquiterpene synthases: Passive catalysts or active players? Nat. Prod. Rep. 2012, 29, 60-71.

(13) Steele, C. L.; Crock, J.; Bohlmann, J.; Croteau, R. Sesquiterpene Synthases from Grand Fir (Abies grandis). J. Biol. Chem. 1998, 273, 2078-2089.

(14) Sugiura, M.; Ito, S.; Saito, Y.; Niwa, Y.; Koltunow, A. M.; Sugimoto, O.; Sakai, H. Molecular Cloning and Characterization of a Linalool Synthase from Lemon Myrtle. Biosci. Biotechnol. Biochem. 2011, 75, 1245-1248.

(15) Alonso, W. R.; Croteau, R. Purification and characterization of the monoterpene cyclase $\gamma$-terpinene synthase from Thymus vulgaris. Arch. Biochem. Biophys. 1991, 286, 511-517.

(16) Frister, T.; Hartwig, S.; Alemdar, S.; Schnatz, K.; Thöns, L.; Scheper, T.; Beutel, S. Characterisation of a Recombinant Patchoulol Synthase Variant for Biocatalytic Production of Terpenes. Appl. Biochem. Biotechnol. 2015, 176, 2185-2201.

(17) Jones, C. G.; Moniodis, J.; Zulak, K. G.; Scaffidi, A.; Plummer, J. A.; Ghisalberti, E. L.; Barbour, E. L.; Bohlmann, J. Sandalwood Fragrance Biosynthesis Involves Sesquiterpene Synthases of Both the Terpene Synthase (TPS)-a and TPS-b Subfamilies, including Santalene Synthases. J. Biol. Chem. 2011, 286, 17445-17454.

(18) O’Maille, P. E.; Chappell, J.; Noel, J. P. Biosynthetic potential of sesquiterpene synthases: Alternative products of tobacco 5-epiaristolochene synthase. Arch. Biochem. Biophys. 2006, 448, 73-82.

(19) Pripdeevech, P.; Wongpornchai, S.; Marriott, P. J. Comprehensive two-dimensional gas chromatography-mass spectrometry analysis of volatile constituents in Thai vetiver root oils obtained by using different extraction methods. Phytochem. Anal. 2010, 21, 163173.

(20) Anthony, K. P.; Deolu-Sobogun, S. A.; Saleh, M. A. Comprehensive Assessment of Antioxidant Activity of Essential Oils. J. Food Sci. 2012, 77, C839-C843.

(21) Alifano, P.; Giudice, L. Del; Talà, A.; Stefano, M. De; Maff, M. E. Microbes at work in perfumery: the microbial community of vetiver root and its involvement in essential oil biogenesis. Flavour Fragrance J. 2010, 25, 121-122.

(22) Chou, S.; Lai, C.; Lin, C.; Shih, Y. Study of the chemical composition, antioxidant activity and anti-inflammatory activity of essential oil from Vetiveria zizanioides. Food Chem. 2012, 134, 262268.

(23) Belhassen, E.; Filippi, J. J.; Brévard, H.; Joulain, D.; Baldovini, N. Volatile constituents of vetiver: A review. Flavour Fragrance J. 2015, 30, 26-82.

(24) Hartwig, S.; Frister, T.; Alemdar, S.; Li, Z.; Scheper, T.; Beutel, S. SUMO-fusion, purification, and characterization of a $(+)$-zizaene synthase from Chrysopogon zizanioides. Biochem. Biophys. Res. Commun. 2015, 458, 883-889.

(25) O'Maille, P. E.; Chappell, J.; Noel, J. P. A single-vial analytical and quantitative gas chromatography-mass spectrometry assay for terpene synthases. Anal. Biochem. 2004, 335, 210-217.

(26) Hong, Y. J.; Tantillo, D. J. Consequences of conformational preorganization in sesquiterpene biosynthesis: Theoretical studies on the formation of the bisabolene, curcumene, acoradiene, zizaene, cedrene, duprezianene, and sesquithuriferol sesquiterpenes. J. Am. Chem. Soc. 2009, 131, 7999-8015.

(27) Martinez, J.; Rosa, P. T. V.; Menut, C.; Leydet, A.; Brat, P.; Pallet, D.; Meireles, M. A. A. Valorization of brazilian vetiver (Vetiveria zizanioides (L.) Nash ex Small) oil. J. Agric. Food Chem. 2004, 52, 6578-6584.
(28) Zellner, B. D.; Amorim, A. C. L.; de Miranda, A. L. P.; Alves, R. J. V.; Barbosa, J. P.; da Costa, G. L.; Rezende, C. M. Screening of the odour-activity and bioactivity of the essential oils of leaves and flowers of Hyptis passerina Mart. from the Brazilian Cerrado. J. Braz. Chem. Soc. 2009, 20, 322-332.

(29) Tholl, D. Terpene synthases and the regulation, diversity and biological roles of terpene metabolism. Curr. Opin. Plant Biol. 2006, 9, 297-304.

(30) Buchanan, B. B.; Gruissem, W.; Jones, R. L. Biochemistry and Molecular Biology of Plants, 2nd ed.; Wiley Blackwell, 2015; pp 11280.

(31) Munk, S. L.; Croteau, R. Purification and Characterization of the Sesquiterpene Cyclase Patchoulol Synthase from Pogostemon cablin. Arch. Biochem. Biophys. 1990, 282, 58-64.

(32) Mercke, P.; Crock, J.; Croteau, R.; Brodelius, P. E. Cloning, Expression, and Characterization of epi-Cedrol Synthase, a Sesquiterpene Cyclase from Artemisia annua L. Arch. Biochem. Biophys. 1999, 369, 213-222.

(33) Hartwig, S.; Frister, T.; Alemdar, S.; Li, Z.; Krings, U.; Berger, R. G.; Scheper, T.; Beutel, S. Expression, purification and activity assay of a patchoulol synthase cDNA variant fused to thioredoxin in Escherichia coli. Protein Expression Purif. 2014, 97, 61-71.

(34) Chahal, K. K.; Bhardwaj, U.; Kaushal, S.; Sandhu, A. K. Chemical composition and biological properties of Chrysopogon zizanioides (L.) Roberty syn. Vetiveria zizanioides (L.) Nash-A Review. Indian J. Nat. Prod. Resour. 2015, 6, 251-260.

(35) Köllner, T. G.; Schnee, C.; Li, S.; Svatoš, A.; Schneider, B.; Gershenzon, J.; Degenhardt, J. Protonation of a neutral (S)- $\beta$ bisabolene intermediate is involved in (S)- $\beta$-macrocarpene formation by the maize sesquiterpene synthases TPS6 and TPS11. J. Biol. Chem. 2008, 283, 20779-20788.

(36) Picaud, S.; Olsson, M. E.; Brodelius, M.; Brodelius, P. E. Cloning, expression, purification and characterization of recombinant (+)-germacrene D synthase from Zingiber officinale. Arch. Biochem. Biophys. 2006, 452, 17-28.

(37) Rising, K. A.; Starks, C. M.; Noel, J. P.; Chappell, J. Demonstration of germacrene $\mathrm{A}$ as an intermediate in 5-Epiaristolochene synthase catalysis. J. Am. Chem. Soc. 2000, 122, $1861-1866$.

(38) Mathis, J. R.; Back, K.; Starks, C.; Noel, J.; Poulter, C. D.; Chappell, J. Pre-steady-state study of recombinant sesquiterpene cyclases. Biochemistry 1997, 36, 8340-8348.

(39) Frister, T. H. W. Herstellung, Charakterisierung und Anwendung einer rekombinanten Patchoulolsynthase zur biokatalytischen Herstellung von Sesquiterpenen. Thesis, Leibniz Hannover Universität, 2015.

(40) Prisic, S.; Peters, R. J. Synergistic Substrate Inhibition of entCopalyl Diphosphate Synthase: A Potential Feed-Forward Inhibition Mechanism Limiting Gibberellin Metabolism. Plant Physiol. 2007, $144,445-454$

(41) Crock, J.; Wildung, M.; Croteau, R. Isolation and bacterial expression of a sesquiterpene synthase cDNA clone from peppermint (Mentha x piperita, L.) that produces the aphid alarm pheromone (E)$\beta$-farnesene. Proc. Natl. Acad. Sci. U.S.A. 1997, 94, 12833-12838.

(42) Landmann, C.; Fink, B.; Festner, M.; Dregus, M.; Engel, K.-H.; Schwab, W. Cloning and functional characterization of three terpene synthases from lavender (Lavandula angustifolia). Arch. Biochem. Biophys. 2007, 465, 417-429.

(43) Mahattanatawee, K.; Perez-Cacho, P. R.; Davenport, T.; Rouseff, R. Comparison of three lychee cultivar odor profiles using gas chromatography - Olfactometry and gas chromatography - Sulfur detection. J. Agric. Food Chem. 2007, 55, 1939-1944.

(44) Politeo, O.; Jukic, M.; Milos, M. Chemical composition and antioxidant capacity of free volatile aglycones from basil (Ocimum basilicum L.) compared with its essential oil. Food Chem. 2007, 101, $379-385$

(45) Stashenko, E. E.; Cervantes, M.; Combariza, Y.; Fuentes, H.; Martinez, J. R. HRGC FID and HRGC MSD analysis of the secondary metabolites obtained by different extraction methods from 
Lepechinia schiedeana, and in vitro evaluation of its antioxidant activity. J. High Resolut. Chromatogr. 1999, 22, 343-349.

(46) Varming, C.; Andersen, M. L.; Poll, L. Volatile monoterpenes in black currant (Ribes nigrum L.) juice: Effects of heating and enzymatic treatment by $\beta$-glucosidase. J. Agric. Food Chem. 2006, 54, 22982302.

(47) Verzera, A.; Trozzi, A.; Zappalá, M.; Condurso, C.; Cotroneo, A. Essential oil composition of Citrus meyerii Y. Tan. and Citrus medica L. cv. Diamante and their lemon hybrids. J. Agric. Food Chem. 2005, 53, 4890-4894.

(48) Aubert, C.; Chanforan, C. Postharvest changes in physicochemical properties and volatile constituents of apricot (Prunus armeniaca L.). Characterization of 28 cultivars. J. Agric. Food Chem. 2007, 55, 3074-3082.

(49) Peña, R. M.; Barciela, J.; Herrero, C.; García-Martín, S. Optimization of solid-phase microextraction methods for GC-MS determination of terpenes in wine. J. Sci. Food Agric. 2005, 85, 12271234.

(50) Brat, P.; Rega, B.; Alter, P.; Reynes, M.; Brillouet, J. M. Distribution of volatile compounds in the pulp, cloud, and serum of freshly squeezed orange juice. J. Agric. Food Chem. 2003, 51, 34423447.

(51) Bartley, J. P.; Jacobs, A. L. Effects of drying on flavour compounds in Australian-grown ginger (Zingiber officinale). J. Sci. Food Agric. 2000, 80, 209-215.

(52) Seo, W. H.; Baek, H. H. Identification of characteristic aromaactive compounds from water dropwort (Oenanthe javanica DC.). J. Agric. Food Chem. 2005, 53, 6766-6770.

(53) Kampranis, S.; Ioannidis, D.; Purvis, A.; Mahrez, W.; Ninga, E.; Katerelos, N. A.; Anssour, S.; Dunwell, J. M.; Degenhardt, J.; Makris, A. M.; Goodenough, P. W.; Johnson, C. B. Rational Conversion of Substrate and Product Specificity in a Salvia Monoterpene Synthase: Structural Insights into the Evolution of Terpene Synthase Function. Plant Cell 2007, 19, 1-13.

(54) Schnee, C.; Köllner, T. G.; Gershenzon, J.; Degenhardt, J. The Maize Gene terpene synthase 1 Encodes a Sesquiterpene Synthase Catalyzing the Formation of (E)- $\beta$-Farnesene, (E)-Nerolidol, and (E,E)-Farnesol after Herbivore Damage. Plant Physiol. 2002, 130, 2049-2060.

(55) Rupasinghe, H. P. V.; Paliyath, G.; Murr, D. P. Sesquiterpene $\alpha$ Farnesene Synthase: Partial Purification, Characterization, and Activity in Relation to Superficial Scald Development in Apples. J. Am. Soc. Hortic. Sci. 1998, 123, 882-886.

(56) Picaud, S.; Brodelius, M.; Brodelius, P. E. Expression, purification, and characterization of recombinant amorpha-4,11diene synthase from Artemisia annua L. Phytochemistry 2005, 66, 961-967.

(57) Vedula, L. S.; Rynkiewicz, M. J.; Pyun, H.; Coates, R. M.; Cane, D. E.; Christianson, D. W. Molecular Recognition of the Substrate Diphosphate Group Governs Product Diversity in Trichodiene Synthase Mutants. Biochemistry 2005, 44, 6153-6163.

(58) Vedula, L. S.; Cane, D. E.; Christianson, D. W. Role of Arginine-304 in the Diphosphate-Triggered Active Site Closure Mechanism of Trichodiene Synthase. Biochemistry 2005, 44, 12719-12727.

(59) López-Gallego, F.; Wawrzyn, G. T.; Schmidt-Dannert, C. Selectivity of Fungal Sesquiterpene Synthases: Role of the Active Site's H-1 $\alpha$ Loop in Catalysis. Appl. Environ. Microbiol. 2010, 76, $7723-7733$.

(60) Lopez-Gallego, F.; Agger, S. A.; Pella, D. A.; Distefano, M. D.; Schmidt-Dannert, C. Sesquiterpene synthases Cop4 and Cop6 from Coprinus cinereus: Catalytic promiscuity and cyclization of farnesyl pyrophosphate geometrical isomers. Chembiochem 2010, 11, 10931106.

(61) Rodríguez-Aparicio, L. B.; Reglero, A.; Ortiz, A. I.; Luengo, J. $M$. Effect of physical and chemical conditions on the production of colominic acid by E. coli in defined medium. Appl. Microbiol. Biotechnol. 1988, 27, 474-483.
(62) van Den Dool, H.; Kratz, P. A generalization of the retention index system including linear temperature programmed gas-liquid partition chromatography. J. Chromatogr. A 1963, 11, 463-471.

(63) Copeland, R. A. Enzymes: A Practical Introduction to Structure, Mechanism, and Data Analysis, 2nd ed.; Wiley-VCH, 2000; pp 1-416.

(64) Biasini, M.; Bienert, S.; Waterhouse, A.; Arnold, K.; Studer, G.; Schmidt, T.; Kiefer, F.; Cassarino, T. G.; Bertoni, M.; Bordoli, L.; Schwede, T. SWISS-MODEL: modelling protein tertiary and quaternary structure using evolutionary information. Nucleic Acids Res. 2014, 42, W252-W258.

(65) Morris, G. M.; Huey, R.; Lindstrom, W.; Sanner, M. F.; Belew, R. K.; Goodsell, D. S.; Olson, A. J. AutoDock4 and AutoDockTools4: Automated docking with selective receptor flexibility. J. Comput. Chem. 2009, 30, 2785-2791.

(66) Pettersen, E. F.; Goddard, T. D.; Huang, C. C.; Couch, G. S.; Greenblatt, D. M.; Meng, E. C.; Ferrin, T. E. UCSF Chimera - A visualization system for exploratory research and analysis. J. Comput. Chem. 2004, 25, 1605-1612.

(67) Dundas, J.; Ouyang, Z.; Tseng, J.; Binkowski, A.; Turpaz, Y.; Liang, J. CASTp: computed atlas of surface topography of proteins with structural and topographical mapping of functionally annotated residues. Nucleic Acids Res. 2006, 34, W116-W118. 